\title{
O ciclo do café durante a República Velha: uma análise com a abordagem de dinâmica de sistemas
}

\author{
Palauras-chave \\ dinâmica de sistemas, \\ República Velha, commodities, \\ políticas de valorização \\ do café.
}

\section{Classificação JEL C63, N56,} Q13.

\footnotetext{
Keywords

system dynamics,

Old Republic, commodities,

coffee valorization policies.
}

JEL Classification C63, N56, Q13.

\section{Resumo}

O objetivo deste trabalho é fazer uma análise sistêmica da dinâmica da produção cafeeira no Brasil com foco no período 1900-1930. A motivação para abordar a questão sob a ótica da dinâmica de sistemas (system dynamics) é que essa metodologia é especialmente adequada para modelar processos sujeitos à complexidade dinâmica, como os ciclos de produção de commodities. Mostrar-se-á que modelar e simular a dinâmica da produção de café no Brasil com essa metodologia permite, em primeiro lugar, realizar experimentos contra-factuais que possibilitam avaliar quantitativamente o efeito de políticas de defesa de preços, como as políticas de valorização, complementando a já extensa e rica literatura sobre o assunto. Em segundo lugar, será sugerido que abordar a questão sob esta ótica ajuda a extrair insights de política não apenas para o café como para outras commodities, das quais o Brasil ainda depende de forma importante para manter o equilíbrio em suas contas externas.

\section{Abstract}

The purpose of this work is to perform a systemic analysis of coffee production in Brazil in the period 1900-1930. The motivation to use system dynamics is that such methodology seems especially suitable to model processes subject to dynamic complexity, such as commodity cycles. Firstly, it will be shown that modeling and simulating the dynamics of coffee production in Brazil with this methodology enables to assess in a quantitative manner through counter-factual experiments the effects of price protection policies, which might complement the rich literature available on the subject. Secondly, it will be suggested that approaching the subject under that lens may allow the obtaining of insights on economic policy for other Brazilian important commodities beyond coffee. 


\section{1_Introdução}

O objetivo deste trabalho é fazer uma análise sistêmica da dinâmica da produção cafeeira no Brasil com foco no período 1900-1930. A motivação para abordar a questão sob a ótica da dinâmica de sistemas (system dynamics) é que essa metodologia é especialmente adequada para modelar processos sujeitos à complexidade dinâmica, como ciclos de produção de commodities. Mostrar-se-á que modelar e simular a dinâmica da produção de café no Brasil com essa metodologia permite, em primeiro lugar, extrair conclusões não intuitivas sobre o processo, como o efeito das políticas de valorização, complementando a já extensa e rica literatura sobre o assunto. Em segundo lugar, será sugerido que abordar a questão sob essa ótica talvez ajude a extrair insights para compreender a dinâmica de longo prazo da produção de outras commodities das quais o Brasil ainda depende de forma importante para manter o equilíbrio em suas contas externas.

O trabalho está organizado do seguinte modo. A seção 2 resume os principais pontos de consenso e de controvérsia na literatura sobre o café durante o período da República Velha e formula a hipótese a ser testada no trabalho. A seção 3 descreve os elementos da me- todologia de dinâmica de sistemas indispensáveis para seguir a discussão, e a seção 4 apresenta um modelo simplificado da dinâmica cafeeira, na forma de uma estrutura estoque-fluxo. Ainda na seção 4, procede-se a análises de sensibilidade do modelo, principalmente em relação aos efeitos das políticas de valorização sobre a dinâmica cafeeira. A seção 5 conclui, discutindo algumas questões relevantes suscitadas pelas simulações, tais como se teriam as políticas de valorização mais beneficiado ou prejudicado a evolução da economia brasileira nos anos futuros e se é possível adotar medidas para tornar menos volátil a produção de outras commodities importantes.

\section{2_Pontos consensuais e controversos na historiografia sobre o café}

A República Velha e a história do café durante esse período são um dos temas mais competentemente estudados pela historiografia econômica brasileira, cujos textos clássicos são de amplo conhecimento mesmo do público não especializado no tema. Assim não parece necessário resumir em detalhe essas interpretações para focalizar nossa discussão, mas apenas sublinhar algumas conclusões consensuais e pontos con- 
troversos nessa literatura e que interessam mais diretamente ao trabalho:

i. As três primeiras operações valorizadoras - 1906, 1917 e 1921 - e o programa de valorização permanente, em seus primeiros anos, foram políticas bem-sucedidas em termos de sustentação dos preços do café, embora haja divergências sobre o efeito dessas políticas no longo prazo.

A principal fonte de divergência sobre as operações valorizadoras diz respeito ao grau de eficiência alocativa dessas operações em termos de fatores de produção e, portanto, de seus efeitos sobre a taxa de crescimento econômico de longo prazo. Delfim Neto (1973), por exemplo, considera que principalmente a valorização permanente tenha tido efeitos negativos sobre o crescimento de longo prazo, ao enviar sinais errados para os produtores, os quais induziram a retenção na cafeicultura de fatores produtivos, que poderiam ser empregados mais eficientemente na indústria. Para Fritsch (1988), essa visão deixa de considerar o fato fundamental, identificado primeiramente por Dean (1971) e depois incorporado consensualmente pela literatura posterior, de que a cafeicultura era altamente complementar à indústria, de modo que a valorização, ao proteger a primeira, afeta- va favoravelmente também a segunda. A valorização como política geral, portanto, mesmo a valorização permanente paulista segundo esta última interpretação, teria sido uma medida correta, influenciando beneficamente o crescimento econômico de longo prazo.

ii. $\mathrm{O}$ fracasso da valorização permanente foi um fator importante para explicar a crise de superprodução em 1929, embora as razões desse fracasso sejam controversas.

Esta questão está diretamente relacionada com a anterior, mas inclui uma dimensão que não está explícita naquela e que é útil assinalar nesta etapa do argumento. Villela e Suzigan (1973), por exemplo, atribuem a crise da cafeicultura em 1929, que cria o contexto econômico para o embate político que culmina com a Revolução de 1930, à superprodução induzida endogenamente pelas operações de valorização. Nesse sentido, pode-se dizer que essa visão se identifica, neste ponto, com a tese de Delfim Neto sobre os efeitos negativos de longo prazo da política de valorização. A mesma conclusão é obtida por Furtado (1986). Para o autor, as políticas de valorização criaram as bases para um ciclo de retroalimentação no mercado cafeeiro, no qual as altas dos preços faziam com que no- 
vos produtores ingressassem no mercado, aumentando a oferta e alimentando futuras intervenções. Fritsch (1988), novamente, opõe-se a essa ideia, considerando que, mais do que efeitos endógenos e de certo modo inevitáveis, a ruptura do mercado de café deveu-se a mudanças nas condições de crédito internacional para financiar o prosseguimento da defesa, bem como a decisões inadequadas de política econômica. Tais decisões tiveram, por um lado, um fundamento teórico errôneo: a tese de que as exportações de café eram elásticas e que, portanto, a queda de preços que decorreria da suspensão da valorização aumentaria as receitas cambiais. Mas, por outro lado, têm uma explicação na esfera da política: a ruptura da aliança política entre São Paulo e Minas Gerais que havia avalizado as operações de valorização anteriores.

Os pontos de debate e consenso acima suscitam a seguinte hipótese, que vamos testar no restante do trabalho. As políticas de valorização tiveram efeito favorável no curto prazo na medida em que, ao assegurarem a manutenção de renda do setor cafeeiro, mantiveram a economia em funcionamento normal durante a maior parte da República Velha. Em longo prazo, entretanto, elas amplificaram o ciclo endógeno do café e finalmente levaram à grande crise de superprodução de 1929.

A hipótese parece plausível no sentido de que políticas pró-cíclicas tendem intuitivamente a acentuar o ciclo endógeno, seja ele de bens manufaturados, seja ele de commodities. No caso do café, especificamente, a dinâmica cíclica endógena decorre em grande parte de características inerentes ao processo produtivo, mas pode ser amplificada por políticas como a de valorização. A explicação é a seguinte.

O café é uma cultura permanente, na qual, no início do século passado, cerca de $75 \%$ dos custos totais eram fixos e apenas $25 \%$ eram variáveis, isto é, dependiam do tamanho da colheita (Bacha, 1992a). Essa importância dos custos fixos, aliada ao fato de que o pé de café só estava apto a começar a produzir após quatro anos do plantio, atingindo a máxima capacidade de produção nove anos depois, mostra que, após significativa expansão da demanda, se seguiria algum tempo até que a produção pudesse suprir essa demanda crescente. Ou seja, os preços continuariam elevados por um grande período antes da reação da oferta. Quando a oferta finalmente aumentasse, a tendência era de uma superprodução, 
uma vez que, na ausência de sinais negativos no preço, as plantações se desenvolviam além do requerido para atender ao crescimento da demanda. Dessa forma, um período de escassez na oferta era inevitavelmente seguido por um período de superprodução.

Mas, mesmo que a hipótese seja verdadeira, isto é, que as políticas de valorização tenham contribuído em alguma medida para acentuar o caráter cíclico da produção cafeeira, isso não significa necessariamente que elas não devessem ter sido adotadas. A resposta a essa questão depende necessariamente da magnitude dos efeitos positivos e envolvidos. Para testarmos a hipótese proposta e suas implicações, portanto, temos de dispor de uma metodologia que permita analisar o que teria acontecido se essas políticas não tivessem sido adotadas e compararmos tais trajetórias contrafactuais com as observadas. A dinâmica de sistemas fornece os instrumentos para realizarmos esse tipo de experimento.

\section{3_A dinâmica de sistemas como referência para modelagem de mercados de "commodities"}

Sistemas são conjuntos de elementos organizados intencionalmente pela ação humana ou que simplesmente se auto- organizam para cumprir propósitos específicos. O sistema elétrico de um automóvel é um exemplo do primeiro tipo, e uma biota não explorada por seres humanos, um exemplo do segundo tipo de sistemas. Os sistemas econômicos são de um terceiro tipo que envolve tanto elementos de intencionalidade quanto de auto-organização. Os três tipos de sistema podem exibir graus consideráveis de complexidade, mas apenas os do segundo e do terceiro tipos definem-se como sistemas dinamicamente complexos.

Complexidade dinâmica é uma propriedade decorrente do fato de que, em sistemas que a exibem, se encontram presentes diferentes agentes, que atuam em condições de racionalidade limitada, que respondem muitas vezes com retardo a informações exógenas ou geradas pelo próprio comportamento do sistema. A presença dessa propriedade implica que o sistema pode responder de forma não intencional do ponto de vista dos agentes que tentam influir sobre ele, isto é, a presença de complexidade dinâmica é uma pré-condição para que um sistema seja capaz de se auto-organizar. É fácil ver, então, que sistemas caracterizados por extrema complexidade de detalhes podem ser dinamicamente simples, na medida em que não envol- 
vam agentes capazes de responder a novas informações, e sistemas relativamente simples em termos de detalhes podem ser dinamicamente complexos.

A propriedade de auto-organização ou emergência ocorre porque, em sistemas dinamicamente complexos, as decisões individuais encontram-se interligadas em malhas de retroalimentação (feedback). Sistemas dinamicamente simples evidentemente podem também envolver ciclos de retroalimentação, como no caso de um aparelho de ar-condicionado, que mantém uma temperatura pré-programada em um ambiente, mas, se devidamente projetados, não são capazes de gerar consequências não pretendidas, a não ser em caso de falha do equipamento. Já em sistemas dinamicamente complexos (em que se encontram inseridos agentes não perfeitamente racionais), consequências não intencionais podem facilmente ocorrer, pelo simples fato de que, por exemplo, os agentes tentam antecipar, de forma muitas vezes difícil de prever, a reação dos demais.

A dinâmica de sistemas (system $d y$ namics) é uma metodologia desenvolvida exatamente para rastrear as consequências de ações isoladas sobre o comportamento de variáveis que se encontram interligadas em malhas de retroalimenta- ção, em que as relações entre causas e consequências estão geralmente distanciadas no tempo, isto é, em que as variáveis relacionam-se com defasagens temporais normalmente não captadas em nosso modelo mental. ${ }^{1}$

A metodologia de dinâmica de sistemas pode, assim, ser definida sinteticamente como abordagem informação/ ação/consequências, como representado na Figura 1 (Ver Coyle, 1996).

\section{Figura 1_A abordagem de dinâmica de sistemas}

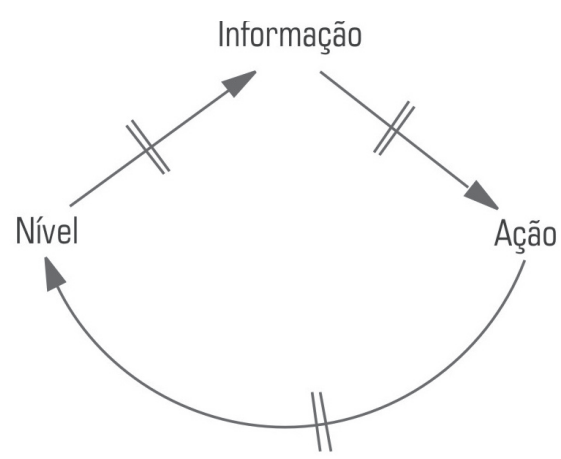

Fonte: Elaboração própria.

Novas informações levam a ações (fluxos), por meio de variáveis auxiliares e parâmetros, que determinam, por exemplo, a elasticidade da oferta de café à variação de preços. Tais ações, em seguida, vão modificar o estado (nível) das condições de um sistema após certa defasagem de tempo (as duas marcas para-
As técnicas incluídas nessa metodologia começaram a ser desenvolvidas pelo pesquisador do Massachussets Institute of Technology Jay Forrester nos anos 60, em uma série de estudos clássicos sobre economia regional e urbana e vem sendo empregadas em estudos aplicados em campos tão distintos do conhecimento como política internacional, ecologia, gestão de recursos naturais e economia. Uma bibliografia de referência básica pode ser obtida em $<$ http:/ /www.systemdynamics. org/short_bibliography. htm>. Uma referência básica para uma visão abrangente da metodologia e das principais técnicas é Sterman (2000). 
lelas sobre a seta indicam a existência de uma defasagem - delay - temporal entre a execução da ação e a mudança no estado do sistema).

As equações fundamentais da dinâmica de sistemas, portanto, são:

$$
\begin{aligned}
\text { Nível }_{t+1}= & \text { Nível }_{t}+\text { Fluxo }_{t+1} \\
\text { Fluxo }_{t+1}= & \mathrm{f}\left(\text { Nível }_{\mathrm{t}},\right. \text { Variáveis } \\
& \text { Auxiliares }_{\mathrm{t}}, \text { Parâmetros) }
\end{aligned}
$$

Mas as mudanças no nível das condições de um sistema geram novas informações para os agentes relevantes, implicando que ação, nível e informação interligam-se em ciclos de retroalimentação. Esses ciclos são de dois tipos. O primeiro é o ciclo de retroalimentação negativa ou de equilíbrio, em que o sistema reage a mudanças, compensando-as. $\mathrm{O}$ segundo tipo é o ciclo de retroalimentação positiva ou de autorreforço, em que o sistema amplifica eventuais perturbações. A dinâmica de um sistema, assim, é comandada pela interação de ciclos de retroalimentação.

Os ciclos de retroalimentação produzem três padrões básicos de comportamento refletidos na taxa de variação líquida da variável de interesse, em nosso caso na produção de café: a) linear, quando o valor absoluto da taxa de variação líquida da variável é cons- tante (isto é, $\mathrm{d}^{2} \mathrm{x} / \mathrm{dt}^{2}=0$ ); b) crescimento ou declínio exponencial, quando o valor absoluto da taxa de variação líquida é crescente (isto é, $\mathrm{d}^{2} \mathrm{x} / \mathrm{dt}^{2}>0$ ); e c) crescimento ou declínio logarítmico, quando o valor absoluto da taxa de variação líquida da variável de interesse decresce no tempo (isto é, $\mathrm{d}^{2} \mathrm{x} / \mathrm{dt}^{2}<0$ ). Combinações desses três padrões são capazes de descrever a maioria dos comportamentos apresentados por sistemas (Ford, 1999). Um comportamento oscilatório ou cíclico, por exemplo, pode ser obtido por ciclos de retroalimentação negativa (que gera crescimento ou declínio logarítmico) com retardos temporais.

A próxima seção desenvolve um modelo que reproduz a dinâmica do café no Brasil utilizando essa abordagem, mas, antes, vejamos por que parece plausível que ela possa de fato ser útil para compreender essa dinâmica.

Muitas commodities experimentam ciclos em preços e produção com características próximas em períodos, amplitudes e fases como exemplificado no Painel A, a seguir. Indústrias sujeitas a longas defasagens temporais na produção e longos ciclos de vida como construtoras de navios, indústria de papel e química igualmente exibem fortes dinâmicas cíclicas; até mesmo alguns setores de 
serviços, como o de seguros, exibem características oscilatórias em preço, rentabilidade e investimento (Sterman, 2000, cap. 20).
Uma explicação frequentemente dada sobre por que a dinâmica de commodities - como o café - é oscilatória é que sua demanda seria cíclica. A afirmação

Painel A_ Produção e preços de boi gordo e cobre nos Estados Unidos

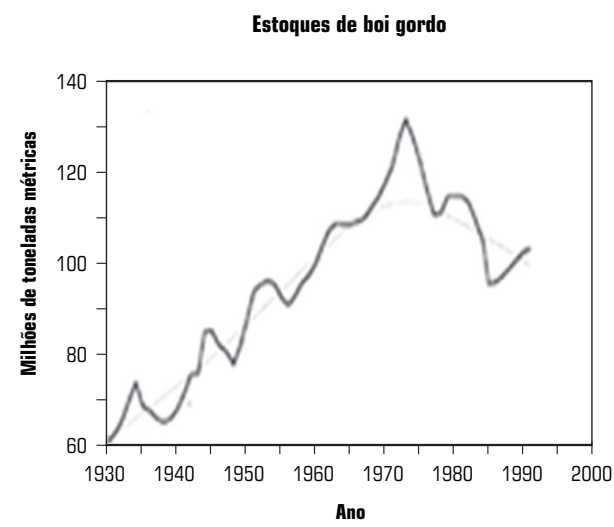

Produção de cobre

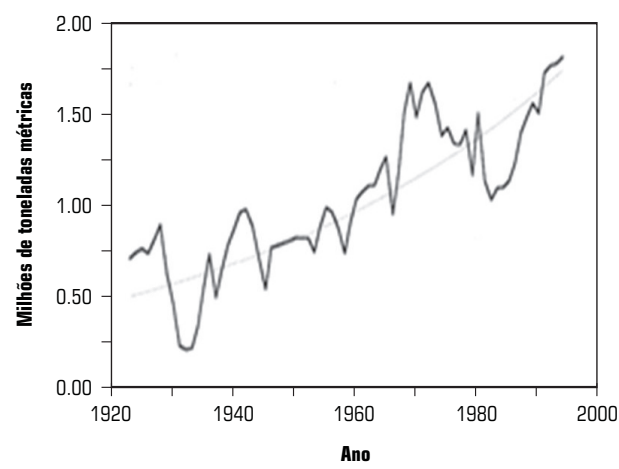

Fonte: Sterman (2000).
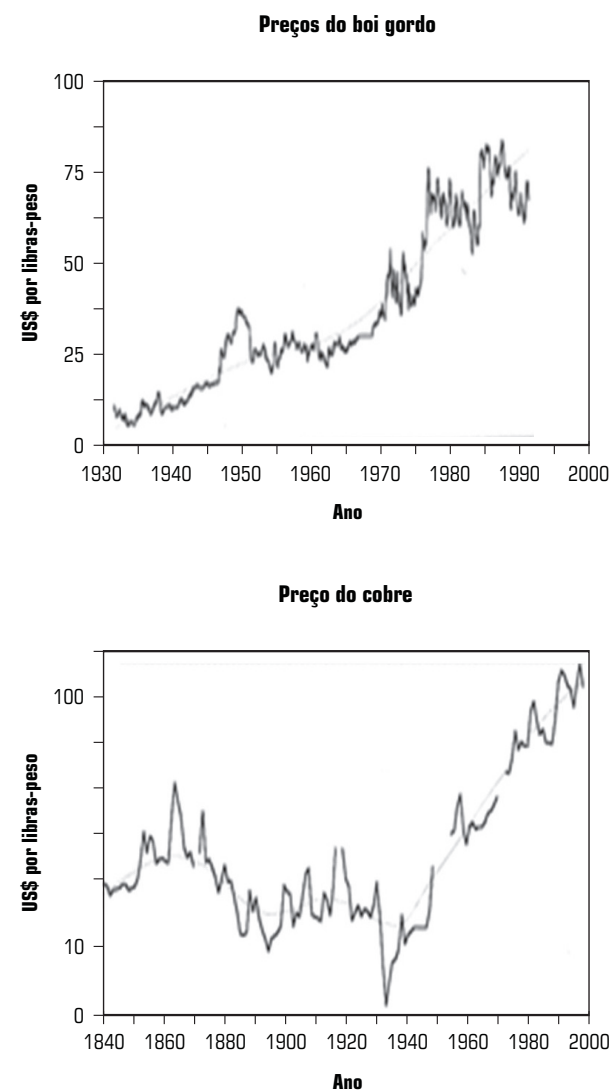
2 O modelo completo em versão Vensim pode ser solicitado diretamente aos autores. é certamente em parte verdadeira, visto que quase todas as economias sofrem de oscilação no crescimento econômico, e que esses movimentos induzem alguma flutuação correspondente nos mercados de commodities. A questão é que esses mercados flutuam geralmente mais do que a economia como um todo, exibindo ciclos com diferentes períodos; às vezes tais ciclos não acompanham o ciclo de crescimento econômico. Isso sugere que a estrutura de retroalimentação endógena à produção de commodities, e não fatores exógenos, possa ser a maior responsável pela oscilação na produção desses bens, o que indica que um modelo sistêmico possa ajudar a compreender melhor a dinâmica de produção de café e de outras commodities.

\section{O modelo do café e seus resultados}

A estrutura estoque-fluxo representada na Figura 2 ajuda a compreender por que a dinâmica geral da produção de café tende a apresentar um padrão histórico oscilatório ${ }^{2}$.

As variáveis dentro dos retângulos são variáveis de nível que acumulam fluxos determinados por parâmetros representativos da estrutura da economia. Assim, por exemplo, o fluxo de sacas de café produzidas em certo ano se acumula na variável de nível Estoque de café. A quantidade de sacas de café produzidas, por sua vez, depende do estoque de cafezais produtivos e de sua produtividade, a qual é um parâmetro estrutural da economia; os sinais positivos sobre os vínculos indicam que existe uma relação direta entre as variáveis, e o sinal negativo, uma relação inversa.

A dinâmica da produção de café obedece a um ciclo de retroalimentação de equilíbrio, assinalado com as linhas mais grossas no diagrama, mas o padrão é oscilatório porque ele ocorre com retardo (delay) temporal. O crescimento da demanda mundial cria um excesso de demanda que leva ao aumento de preços, o que induz o plantio de novos cafezais. Mas os novos cafezais demoram certo tempo para estar em condições de começar a produzir: cerca de sete anos durante o período estudado. Assim, o excesso de demanda tende a persistir até que os novos cafezais se tornem produtivos, o que leva a uma dinâmica de ultrapassagem (overshooting), em que a capacidade produtiva ultrapassa o crescimento da demanda. Quando os novos cafezais tornam-se produtivos, ocorre uma crise de superprodução a qual pode ser mitigada pela política de aquisições governamentais. 
Figura 2_A dinâmica da produção de café

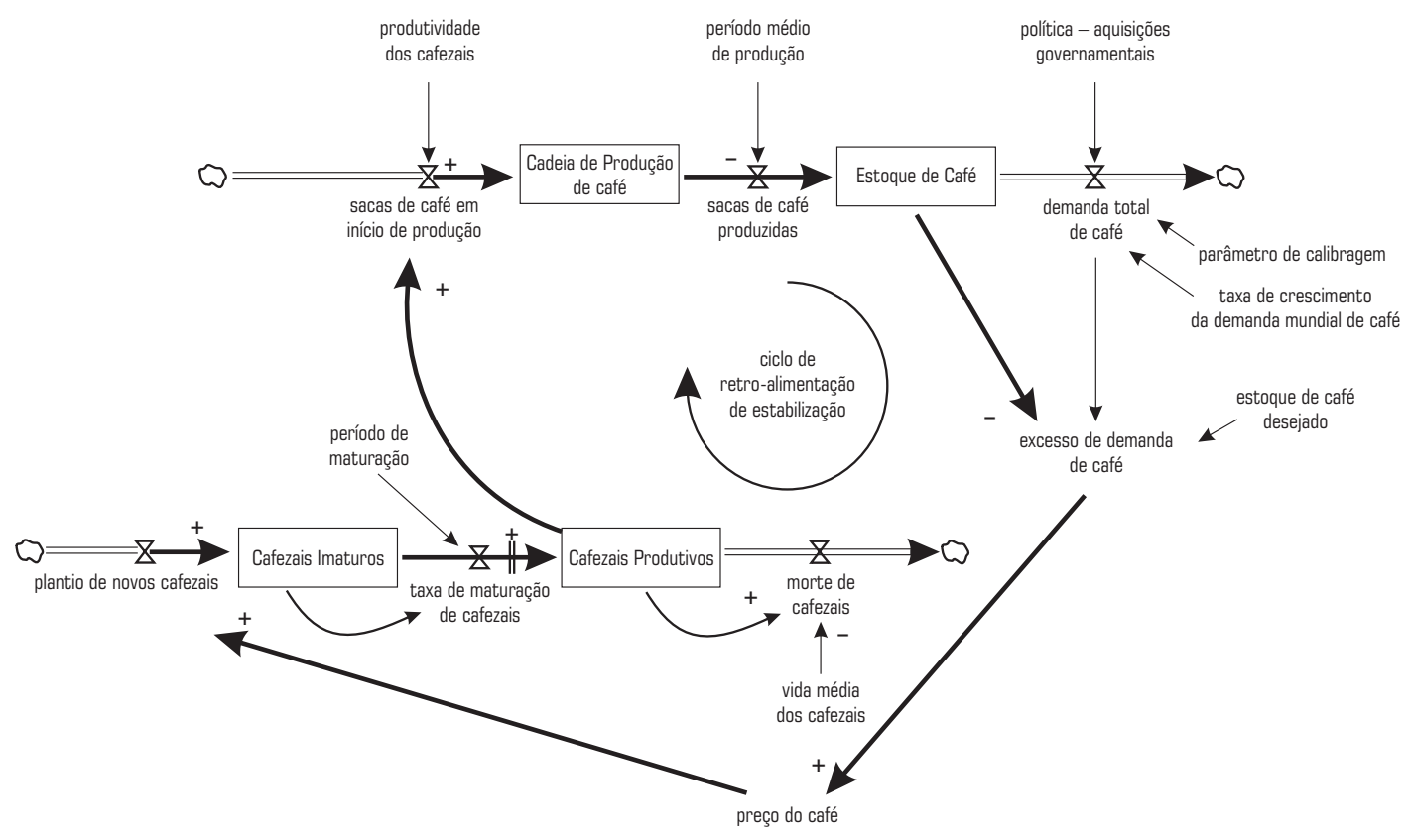

Fonte: Modelo adaptado (Vensim).

A variável política é definida como um acréscimo à taxa de crescimento normal da demanda, ${ }^{3}$ produzido por aquisição governamental nas duas principais operações valorizadoras ocorridas em 1906 e 1917, de 60 e 15 milhõesde sacas, respectivamente (ver Bacha, 1992a). ${ }^{4}$

A influência dos excessos de demanda foi modelada utilizando-se uma função-tabela (table ou look-up function). Nessa especificação, relaciona-se o nível de excesso de demanda ocorrido em pe-
3 O parâmetro de calibragem foi utilizado para estabilizar o modelo, visto que a demanda de café em sacas não reproduz o efeito de valorização ou desvalorização das relações de troca. Assim, um crescimento de, digamos, $11 \%$ no consumo de café em milhões de sacas em um determinado ano não significa necessariamente que a demanda teve excepcional crescimento, mas que talvez o quantum exportado tenha aumentado exatamente para compensar a queda na relação de troca. $\mathrm{O}$ parâmetro de calibragem, assim, ajusta a demanda final de modo a tornar consistente entre si a evolução simulada e observada da produção de café.

4 Não se levaram em consideração as outras duas políticas de valorização, uma vez que isso não alteraria as conclusões qualitativas do exercício. 
ríodos passados com os preços do café em vigor em uma função. A lógica é que, sempre que o excesso de demanda se aproximar de valores observados no passado, o nível de preços reproduzirá os valores desses períodos.

A Figura 3 reproduz a dinâmica do modelo para os parâmetros assumidos acima. Para o que interessa mais diretamente aqui, cumpre observar que o sentido dessa dinâmica não diverge acintosamente das séries históricas de estoque e produção real de café. $\mathrm{O}$ estoque de café, por exemplo, atinge picos nos períodos próximos à adoção das políticas de valorização - 1905 e 1916 - e nos anos em que a economia mundial já se encontrava em depressão.

Mas que papel teriam tido no processo as políticas de valorização? Especificamente, teriam elas sido as responsáveis, ou pelo menos um dos fatores explicativos do padrão oscilatório observado? As simulações a seguir sugerem que não (Figura 4).

Mesmo se desconsiderássemos os efeitos das políticas de valorização, isto é, supondo que as aquisições governamentais tivessem sido zero em 1906 e 1917, o padrão oscilatório permaneceria como mostrado no primeiro gráfico. A única diferença é que os picos no esto-

\section{Figura 3_ Estoque de café com políticas de valorização} - valores simulados e observados

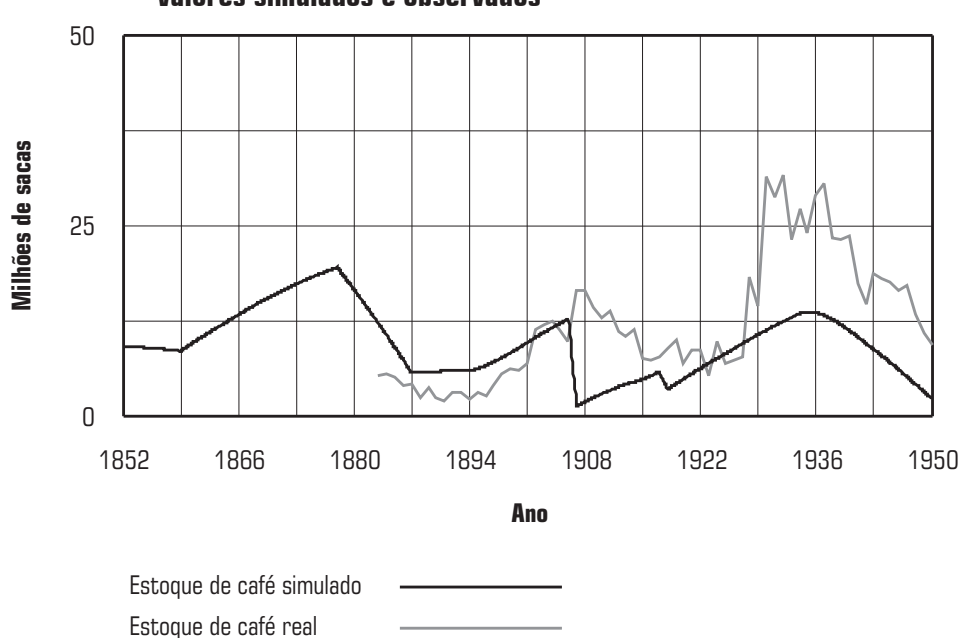

Fonte: Valores simulados: modelo adaptado (Vensim); valores reais: Bacha (1992a). 


\section{Figura 4_Estoque de café com políticas de valorização e sem elas}

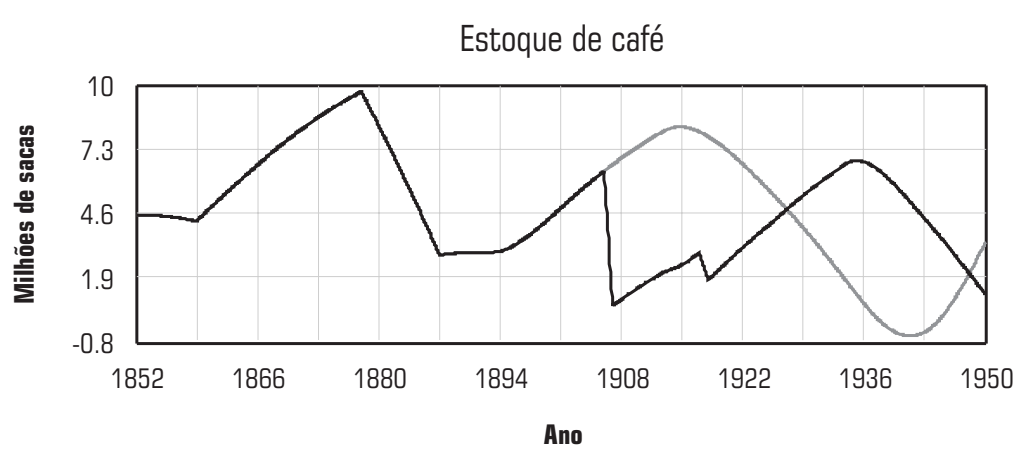

Estoque de café: com política

Estoque de café: sem política

Fonte: Valores simulados: modelo adaptado (Vensim).

que teriam ocorrido em anos diferentes. Se a primeira política de valorização não tivesse sido adotada em 1906, por exemplo, o estoque teria continuado a crescer levando uma crise de superprodução, a ocorrer entre 1908 e 1922. Não teria havido também uma acumulação excessiva de estoque durante a recessão, mas isso apenas porque a economia ainda estaria sentindo os efeitos da crise anterior.

Qual seria, então, a explicação para o padrão cíclico? A explicação mais plausível é que ele é inerente à produção de bens em que investimentos e efetivação da capacidade encontram-se separados por longas defasagens temporais. $\mathrm{Na}$ Figura 5, mostra-se que a volatilida- de da produção de café teria se reduzido significativamente se ocorresse uma redução na defasagem entre plantio e maturação de novos cafezais, ${ }^{5}$ mesmo que nenhuma política de valorização tivesse sido adotada.

A política de valorização, então, não parece poder ser responsabilizada pelo padrão cíclico na produção de café, mas isso não significa necessariamente que ela não tenha produzido efeitos benéficos para a economia no período. A Figura 6, mostra que a adoção de políticas em 1906 e 1917 pode até ter tornado a variação de estoques e, portanto, da produção menos acentuada no período tomado como um todo.
Como, de fato, ocorreu posteriormente com os avanços agronômicos. 
Figura 5_ Estoque de café - diferentes prazos de maturação

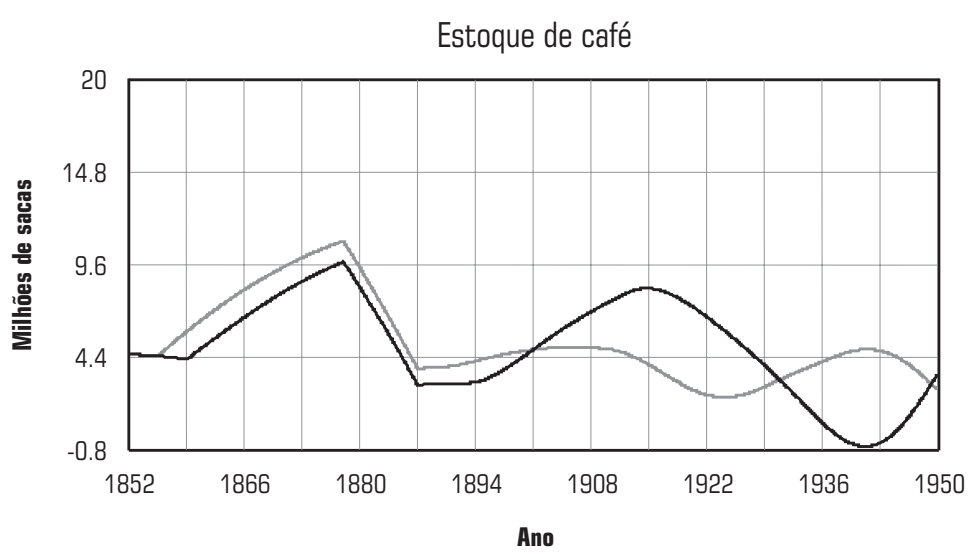

Estoque de café: maturação 7 anos

Estoque de café: maturação 3,5 anos

Fonte: Valores simulados: modelo adaptado (Vensim).

\section{Figura 6_ Estoque de café - com (e sem ) políticas de valorização}

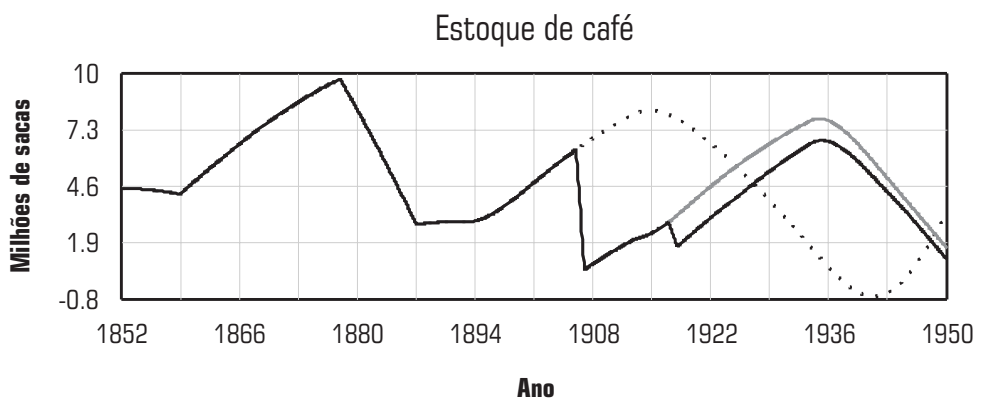

Estoque de café: com política em 1906 e 1917 Estoque de café: com política em 1906 Estoque de café: sem política

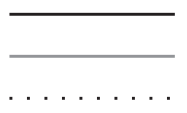

Fonte: Valores simulados: modelo adaptado (Vensim). 


\section{5_Conclusões}

Procurou-se neste trabalho contribuir para a discussão sobre a dinâmica da produção cafeeira durante a República Velha, tentando lançar alguma luz adicional sobre alguns pontos ainda controversos na literatura. Entre esses pontos, um mereceu destaque especial, a saber: se teriam as políticas de valorização contribuído para acelerar a instabilidade da produção e, assim, tido mais efeitos negativos que positivos sobre a economia brasileira no período e posteriormente. Ou se, alternativamente, seus efeitos teriam sido mais positivos, no sentido de que teriam sido indispensáveis para manter nossa economia em funcionamento relativamente normal em face da dependência extrema de uma commodity, o que por si só tenderia a gerar um padrão oscilatório na produção e na evolução dos estoques.

As simulações realizadas apóiam a segunda alternativa, embora estudos mais detalhados precisem ainda ser feitos para conferir mais confiabilidade a essa conclusão. O efeito de aumento da instabilidade cíclica pelas políticas de valorização, se é que ocorreu, foi de pequena magnitude; as políticas de valorização, de acordo com as simulações, teriam produzido mais deslocamentos de vales e picos do que propriamente amplificado o ciclo endógeno do café.

Os ciclos endógenos de commodities resultam da interação de longos retardos na resposta da oferta a variação de preços e da racionalidade limitada dos produtores. Produtores e investidores parecem formar suas expectativas de lucratividade de forma adaptativa, não levando em conta adequadamente as defasagens temporais existentes no sistema ou o impacto das decisões de investimento, produção e preços dos demais produtores, por exemplo, dos concorrentes internacionais. Assim, embora em teoria o processo possa tender a se equilibrar espontaneamente no longo prazo, sua dinâmica endógena é necessariamente oscilatória.

Acresce a isso que as oscilações nesses mercados, diferentemente do que alguns economistas acreditam, não parecem passíveis de ser amortecidas completamente por meio de arbitragem, com investidores calibrando seus investimentos comprando na baixa e vendendo no período de baixa de preços. Tais mecanismos de fato existem, como a ação das casas exportadoras de café estrangeiras no início do século $\mathrm{XX}$, que, ao comprarem na baixa e venderem na alta de preços, contribuíam para amorte- 
cer o ciclo endógeno do café. Como os eventos posteriores demonstraram, entretanto, eles são insuficientes para eliminar oscilações significativas na produção, estoques e preços de commodities. A implicação é que economias altamente dependentes da exportação de bens primários provavelmente não podem se dar ao luxo de não tentar mitigar as flutuações na atividade econômica por meio de políticas.

Isso, é claro, gera um problema fundamental, como apontado por Delfim Neto: ao mitigar o ciclo econômico natural, a política econômica cria uma inércia no sistema, deixando de sinalizar aos produtores as vantagens de uma realocação dos recursos produtivos para a produção de bens menos vulneráveis a flutuações cíclicas endógenas. Mas, ao mesmo tempo, deixa claro que mudanças substanciais na alocação de recursos envolvem uma intrincada teia de trade-offs entre curto e longo prazos, os quais, por isso mesmo, só podem ser avaliados adequadamente com metodologias como a que propusemos neste trabalho. 


\section{Referências bibliográficas}

BACHA, E.; GREENHILL, R. O século XIX. In: MARTINS, Marcellino; E. Johnston Exportadores LTDA. (Org.). 150 anos de café. São Paulo: LIS, 1992a. p. 18-29.

BACHA, E.; GREENHILL, R. O ciclo do café. In: MARTINS, Marcellino E. Johnston Exportadores LTDA. (Org.). 150 anos de café. São Paulo: LIS, 1992b. p. 30-35.

COYLE, R. G. System dynamics modelling - a practical approach. Boca Raton: Chapman \& Hall, 1996.

DEAN, W. A industrialização de São Paulo (1880-1945). São Paulo: Edusp, 1971.

DELFIM NETO, A. O problema do café no Brasil. Ensaios sobre café e desenvolvimento econômico, Rio de Janeiro, IBC, [1959] 1973.

FORD, D. A behavioral approach to feedback loop dominance analysis. System Dynamics Review, v. 15 , n. 1, 1999.

FRITSCH, W. Apogeu e crise na Primeira República: 1900-1930. In: ABREU, M. P. (Org). $A$ ordem do progresso - cem anos de política econômica republicana (18891989). Rio de Janeiro:

Campus, 1988.
FURTADO, C. Formação econômica do Brasil. 21. ed. São Paulo:

Companhia Editora

Nacional, 1986.

STERMAN, J. D. Business dynamics - system thinking and modeling for a complex world. Boston: McGrawHill, 2000. p. 107-133.

VILLELA, A. V.; SUZIGAN,

W. Política do governo e crescimento da economia brasileira. Rio de Janeiro: IPEA/INPES, 1973.

Os autores agradecem ao Conselho
Nacional de Desenvolvimento
Científico e Tecnológico (CNP q) pela
concessão de bolsa que permitiu a
realização da pesquisa e a elaboração
do artigo.
E-mail de contato dos autores:
tcaliaricedeplar.ufmg.br
npbueno@urv.br
Artigo recebido em janeiro de 2009;
aprovado em abril de 2010.

